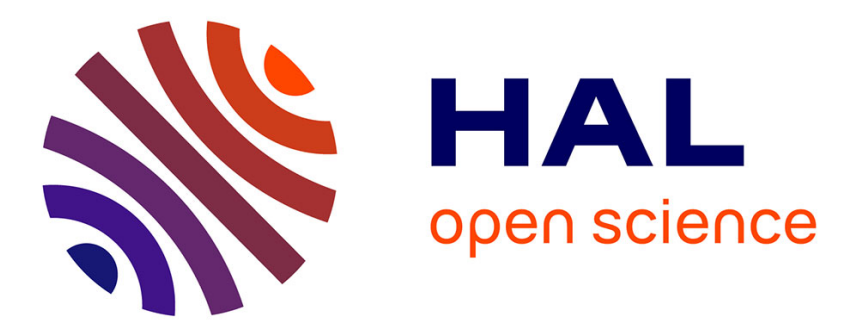

\title{
A comparative study of two Predictive Current Controls for a Permanent Magnet Synchronous Machine drive
}

Florent Morel, Xuefang Lin-Shi, Jean-Marie Rétif, Bruno Allard

\section{To cite this version:}

Florent Morel, Xuefang Lin-Shi, Jean-Marie Rétif, Bruno Allard. A comparative study of two Predictive Current Controls for a Permanent Magnet Synchronous Machine drive. IEEE PESC, Jun 2008, Rhodes, Greece. pp.3068 - 3073, 10.1109/PESC.2008.4592421 . hal-00369422

\section{HAL Id: hal-00369422 https://hal.science/hal-00369422}

Submitted on 3 Jun 2009

HAL is a multi-disciplinary open access archive for the deposit and dissemination of scientific research documents, whether they are published or not. The documents may come from teaching and research institutions in France or abroad, or from public or private research centers.
L'archive ouverte pluridisciplinaire HAL, est destinée au dépôt et à la diffusion de documents scientifiques de niveau recherche, publiés ou non, émanant des établissements d'enseignement et de recherche français ou étrangers, des laboratoires publics ou privés. 


\title{
A Comparative Study of Two Predictive Current Controls for a Permanent Magnet Synchronous Machine Drive
}

\author{
Florent Morel, Xuefang Lin-Shi, Jean-Marie Rétif, Bruno Allard \\ AMPERE — INSA de Lyon \\ Bâtiment Léonard de Vinci \\ 21 avenue Jean Capelle \\ 69621 Villeurbanne Cedex \\ France \\ Email: florent.morel@insa-lyon.fr \\ Telephone: +33472438238 - Fax: +33472438530
}

\begin{abstract}
This paper presents the experimental results-based comparison of two Predictive Current Controls (PCC) for Permanent Magnet Synchronous Machines (PMSM) drives.

The first tested control scheme is based on a model including the inverter and the PMSM and taking into account the discrete nature of the inverter leg states. It predicts the future evolution of the currents for each possible configuration of the inverter. The switching state which minimizes a given cost function is selected. The selected inverter state is applied during the next sampling time.

The second tested control scheme uses a model of the PMSM to predict the output voltages which allow to reach desired currents after one modulation period. A new algebraic method is presented to directly compute the duty cycle of each leg. Then a modulator generates the corresponding gate drive pulses of the inverter.

These two control schemes are tested with a $1.6 \mathrm{~kW}$ PMSM drive at several operating points during steady state and transient operation. A detailed comparison of results is given. Advantages and drawbacks of each method are discussed.
\end{abstract}

\section{INTRODUCTION}

Inverter-fed AC-machines are widely used in industrial applications. When fast torque responses and high-performance operation are required, Permanent Magnet Synchronous Machines (PMSM) are often used and high performance current controls are needed. Many studies have been performed for the development of such algorithms. Among them, methods called Predictive Current Control (PCC) show very good performances compared to classical methods such as Vector Control or Direct Torque Control (DTC). Predictive current controls can be separated into at least two different classes.

The first one, introduced in [1-5], consists in predicting the future value of the load currents for all the voltage vectors the inverter can generate. Then the inverter configuration which minimizes a cost function is selected. So one and only one configuration is selected for application during the next sampling period. This approach is a direct approach since the control variable is directly the inverter switching states (Fig. 1); it is then noted Direct Predictive Control (DPC) in this paper. It is worth to note that this control scheme is quite different from DTC [6]. Indeed with DTC the applied configuration is selected according to a table that is the result of a heuristics and there is no prediction of the future possible load currents.

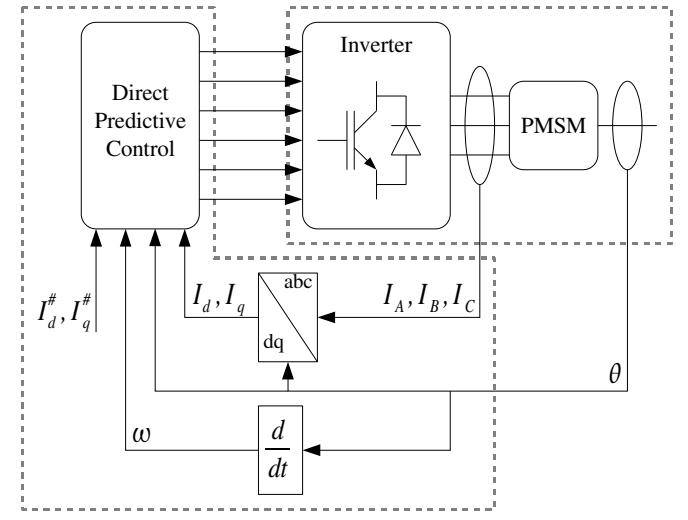

Fig. 1. Direct Predictive Control Principle

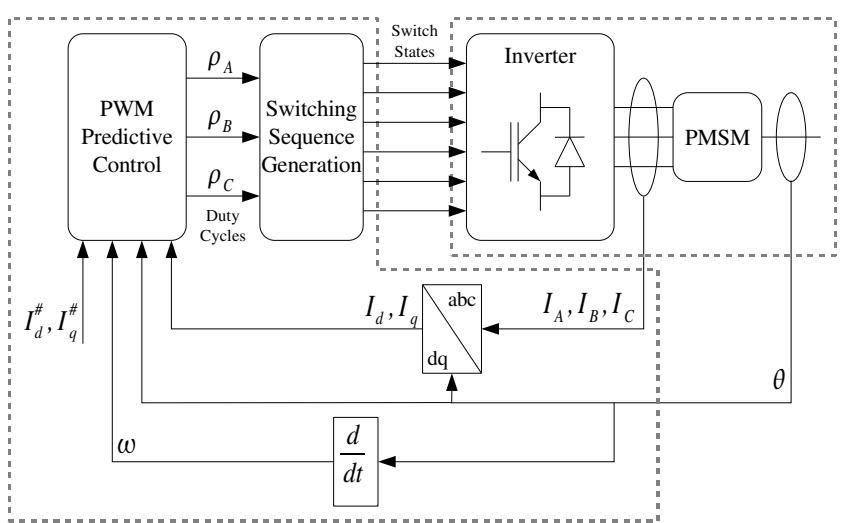

Fig. 2. PWM Predictive Control Principle

The second class of predictive controls predicts the required voltages to reach desired currents after a sampling period. Later a Pulse Width Modulation (PWM) is used to translate these voltages into switching orders [7] (Fig. 2). This approach, sometime called Dead Beat Control $[8,9]$, is noted PWM Predictive Control (PPC) in this paper. It has been used in current control for inverters [10,11], as well as for PMSM [12] where the duty cycles are calculated by using classical Space Vector PWM (SVPWM). A new algebraic method is presented in this paper to directly determine leg duty cycles 


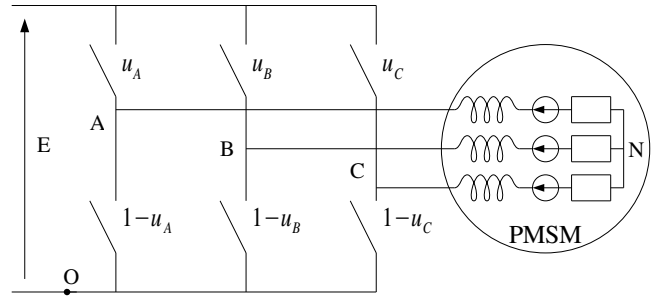

Fig. 3. Simplified Representation of the Considered System

without trigonometrical functions in order to make easier real time implementation compared to a classical SVPWM.

Until now no comparative study between DPC and PPC can be found in literature. This paper expands these two approaches for a PMSM drive. Comparative study is performed with the same test bench with equivalent switching frequency for different operating conditions. Comparative points concerns steady state and dynamic behaviors.

\section{Direct Predictive Control}

\section{A. Model}

A PMSM consists of three phases stator windings and permanent magnets mounted on the rotor surface (Surface Mounted PMSM) or buried inside the rotor (Interior PMSM). This machine can be modeled classically by state-space equation (1) written in the $(d q)$ rotor flux reference frame.

$$
\begin{aligned}
{\left[\begin{array}{c}
\dot{I}_{d}(t) \\
\dot{I}_{q}(t)
\end{array}\right]=\left[\begin{array}{cc}
-\frac{R}{L} & \omega(t) \\
-\omega(t) & -\frac{R}{L}
\end{array}\right] \cdot\left[\begin{array}{c}
I_{d}(t) \\
I_{q}(t)
\end{array}\right] } \\
+\left[\begin{array}{ccc}
\frac{1}{L} & 0 & 0 \\
0 & \frac{1}{L} & -\frac{\omega(t)}{L}
\end{array}\right] \cdot\left[\begin{array}{c}
V_{d}(t) \\
V_{q}(t) \\
\phi
\end{array}\right]
\end{aligned}
$$

In (1) $I_{d}$ and $I_{q}$ are the stator currents expressed in the $d q$ frame, $R$ and $L$ are the stator phase resistance and inductance respectively, $\omega$ is the rotor electrical speed, $V_{d}$ and $V_{q}$ are the stator voltages expressed in the $d q$ reference frame and $\phi$ is the flux established by rotor permanent magnets.

$R, L$ and $\phi$ are considered as constants. So for a short sampling time $T$ which is much smaller than the PMSM electrical and mechanical time constants, it can be assumed that angular rotor position and speed variations can be neglected. In this case, the PMSM can be modeled by discrete-time equations by means of a Taylor expansion. For a first order expansion, Eq. (2) is obtain where $\boldsymbol{F}, \boldsymbol{G}$ and $\underline{H}$ are given in Eq. (3).

$$
\begin{gathered}
{\left[\begin{array}{r}
I_{d}(k+1) \\
I_{q}(k+1)
\end{array}\right]=\boldsymbol{F}(k) \cdot\left[\begin{array}{c}
I_{d}(k) \\
I_{q}(k)
\end{array}\right]+\boldsymbol{G} \cdot\left[\begin{array}{l}
V_{d}(k) \\
V_{q}(k)
\end{array}\right]+\underline{H}(k)} \\
\boldsymbol{F}(k)=\left[\begin{array}{cc}
1-\frac{R T}{L} & T \omega(k) \\
-T \omega(k) & 1-\frac{R T}{L}
\end{array}\right] \\
\boldsymbol{G}=\left[\begin{array}{cc}
\frac{T}{L} & 0 \\
0 & \frac{T}{L}
\end{array}\right] \quad \underline{H}(k)=\left[\begin{array}{c}
0 \\
-\frac{T \omega(k)}{L} \phi
\end{array}\right]
\end{gathered}
$$

For DPC, the vector $\left[\begin{array}{lll}V_{d}(k) & V_{q}(k)\end{array}\right]^{T}$ must be expressed as a function of the inverter switching states. So we define $u_{X}(X \in\{A, B, C\})$ as an integer than represent the state of the leg $X$ (Fig. 3) with the following convention : if $u_{X}=0$ then $V_{X O}=0$; if $u_{X}=1$ then $V_{X O}=E$. Considering the
TABLE I

Correspondence Between the Configuration Number $(i)$ AND The Switching State $(u)$ of Each Leg $(A, B$ or $C)$

\begin{tabular}{ccccccccc}
\hline \hline$i$ & 0 & 1 & 2 & 3 & 4 & 5 & 6 & 7 \\
$u_{A}$ & 0 & 1 & 1 & 0 & 0 & 0 & 1 & 1 \\
$u_{B}$ & 0 & 0 & 1 & 1 & 1 & 0 & 0 & 1 \\
$u_{C}$ & 0 & 0 & 0 & 0 & 1 & 1 & 1 & 1 \\
\hline \hline
\end{tabular}

load is balanced, it can be demonstrated that the phase-toneutral voltages can be expressed as functions of inverter's leg states (4)

$$
\left[\begin{array}{l}
V_{A N}(k) \\
V_{B N}(k) \\
V_{C N}(k)
\end{array}\right]=\frac{E}{3} \cdot\left[\begin{array}{ccc}
2 & -1 & -1 \\
-1 & 2 & -1 \\
-1 & -1 & 2
\end{array}\right] \cdot\left[\begin{array}{l}
u_{A}(k) \\
u_{B}(k) \\
u_{C}(k)
\end{array}\right]
$$

Stator voltages expressed in the $\alpha \beta$ stator reference frame are obtained using Concordia transformation. So using (4) it is possible to express stator voltages in the $\alpha \beta$ reference frame as functions of inverter leg states (5).

$$
\left[\begin{array}{l}
V_{\alpha}(k) \\
V_{\beta}(k)
\end{array}\right]=E \cdot \sqrt{\frac{2}{3}} \cdot\left[\begin{array}{ccc}
1 & -\frac{1}{2} & -\frac{1}{2} \\
0 & \frac{\sqrt{3}}{2} & -\frac{\sqrt{3}}{2}
\end{array}\right] \cdot\left[\begin{array}{l}
u_{A}(k) \\
u_{B}(k) \\
u_{C}(k)
\end{array}\right]
$$

Finally stator voltages in the $(d q)$ rotor flux reference frame can be expressed as functions of inverter leg states by using a rotation matrix $\boldsymbol{M}(k)$ (6).

$$
\begin{aligned}
{\left[\begin{array}{l}
V_{d}(k) \\
V_{q}(k)
\end{array}\right] } & =\boldsymbol{M}(k) \cdot E \sqrt{\frac{2}{3}} \cdot\left[\begin{array}{ccc}
1 & -\frac{1}{2} & -\frac{1}{2} \\
0 & \frac{\sqrt{3}}{2} & -\frac{\sqrt{3}}{2}
\end{array}\right] \cdot\left[\begin{array}{l}
u_{A}(k) \\
u_{B}(k) \\
u_{C}(k)
\end{array}\right] \\
& =\boldsymbol{M}(k) \cdot \boldsymbol{D} \cdot \underline{u}(k)
\end{aligned}
$$

where $\boldsymbol{M}(k)=\left[\begin{array}{cc}\cos \theta(k) & \sin \theta(k) \\ -\sin \theta(k) & \cos \theta(k)\end{array}\right](\theta$ is the angular rotor position), $\underline{u}(k)=\left[\begin{array}{lll}u_{A}(k) & u_{B}(k) & u_{C}(k)\end{array}\right]^{T}$ and $\boldsymbol{D}$ is a constant matrix.

For a two-level three-phase voltage inverter, there are two switching states for each leg, so there are eight possible switching states represented by eight different vectors $\underline{u}(k)$ (Tab. I). Configurations 0 and 7 lead both to zero voltages (free response).

Finally the model used by DPC (7) is obtained by applying (6) in (2).

$$
\underline{X}_{i}(k+1)=\boldsymbol{F}(k) \cdot \underline{X}(k)+\boldsymbol{G} \cdot \boldsymbol{M}(k) \cdot \boldsymbol{D} \cdot \underline{u}_{i}(k)+\underline{H}(k)
$$

In (7) $\underline{X}(k)=\left[\begin{array}{ll}I_{d}(k) & I_{q}(k)\end{array}\right]^{T}$ is the state vector; $\underline{u}_{i}(k)$ is the control vector corresponding to the $i^{\text {th }}$ configuration. This model allows to predict the state vector $\underline{X}_{i}(k+1)$ after a sampling period if the $i^{t h}$ configuration is used.

\section{B. Control Scheme}

At each computation cycle, the direct predictive control scheme measures stator currents and angular position to compute the state vector and matrices $\boldsymbol{F}, \boldsymbol{M}$ and $\underline{H}$ (Fig. 4) For each configuration $i(i=1 \ldots 7)$, a prediction of $\underline{X}_{i}(k+1)$ is calculated by using (7). Then the algorithm selects the configuration which minimizes a cost function $g_{i}$. In this paper the used cost function is the distance between the desired reference state $\underline{X}^{\#}$ and the predicted state vector $\underline{X}_{i}(k+1)$.

$$
\left|\underline{X}_{o p t}(k+1)-\underline{X}^{\#}\right|=\min _{1 \leq i \leq 7}\left|\underline{X}_{i}(k+1)-\underline{X}^{\#}\right|
$$




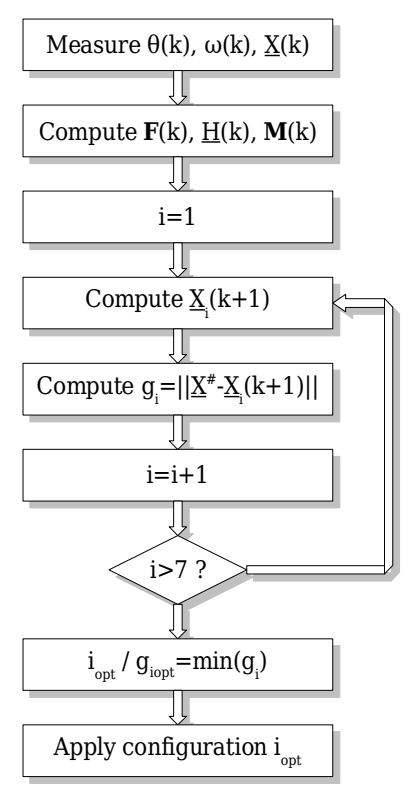

Fig. 4. Steps of Direct Predictive Control

The selected configuration is applied during the next sampling time.

\section{PWM PREDictive CONTROL}

\section{A. Model}

For PWM predictive control, duty cycle of each leg is introduced as follows: $\rho_{X}$ is the duty cycle of the leg $X$ ( $X \in\{A, B, C\}$ ). For a sampling time $T$, if $\overline{V_{d, q}}(k)$ is the mean value of $V_{d, q}(t)$ during this period, it can be written:

$$
\begin{aligned}
\rho_{X}(k) & =\frac{1}{T} \int_{k \cdot T}^{(k+1) T} u_{X}(t) d t \\
\bar{V}_{d, q}(k) & =\frac{1}{T} \int_{k \cdot T}^{(k+1) T} V_{d, q}(t) d t
\end{aligned}
$$

As for (6), stator voltages can be expressed in the $(d q)$ reference frame as functions of the duty cycle vector $\rho(k)=$ $\left[\begin{array}{lll}\rho_{A}(k) & \rho_{B}(k) & \rho_{C}(k)\end{array}\right]^{T}(11):$

$$
\left[\begin{array}{l}
\bar{V}_{d}(k) \\
\bar{V}_{q}(k)
\end{array}\right]=\boldsymbol{M}(k) \cdot \boldsymbol{D} \cdot \underline{\rho}(k)
$$

Then applying (11) in (2) leads to the model (12).

$$
\underline{X}(k+1)=\boldsymbol{F}(k) \cdot \underline{X}(k)+\boldsymbol{G} \cdot \boldsymbol{M}(k) \cdot \boldsymbol{D} \cdot \underline{\rho}(k)+\underline{H}(k)
$$

\section{B. Control Scheme}

In a conventional PWM predictive control [10], the stator voltages which force the state vector to reach the reference currents are computed using the model (2). These voltages are obtained with (13) under the condition that $\boldsymbol{G}$ is invertible:

$$
\left[\begin{array}{l}
V_{d}(k) \\
V_{q}(k)
\end{array}\right]=\boldsymbol{G}^{-1}\left(\underline{X}^{\#}-\boldsymbol{F}(\omega) \cdot \underline{X}(k)-\underline{H}(\omega)\right)
$$

A classical space vector Pulse-Width Modulation (PWM) generator is used to translate these voltages to switching signals applied to gate drivers.

Generally the used relationship between the voltage space vector and the calculated voltages depends on trigonometrical functions as shown in [12]. As a consequence the implementation is difficult if Field-Programmable Gate Array (FPGA) or

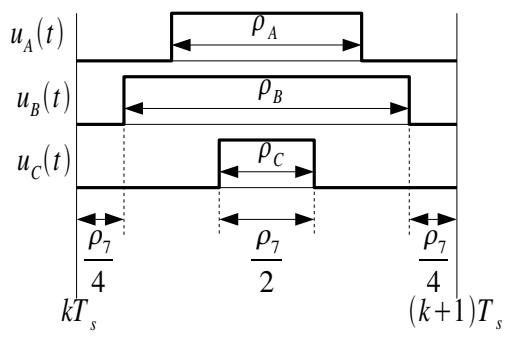

Fig. 5. Example of Switching Sequence During a Modulation Period

Erasable Programmable Logic Devices (EPLDs) are used and the calculation duration is large if a Digital Signal Processor (DSP) is used.

The proposed PWM predictive control uses the model (12) to directly determine duty cycles $\underline{\rho}(k)$ as explained in the following section.

\section{Duty Cycle Calculation}

Since $\boldsymbol{G}$ and $\boldsymbol{M}$ are invertibles (14) can be used in order to calculate the duty cycles which allows to reach the desired state vector $\underline{X}^{\#}$ in one modulation period.

$$
\boldsymbol{D} \cdot \underline{\rho}(k)=\boldsymbol{M}^{-1}(k) \cdot \boldsymbol{G}^{-1} \cdot\left(\underline{X}^{\#}-\boldsymbol{F}(k) \cdot \underline{X}(k)-\underline{H}(k)\right)
$$

By replacing $D$ by its expression, (14) becomes (15).

$$
\begin{aligned}
& {\left[\begin{array}{ccc}
1 & -\frac{1}{2} & -\frac{1}{2} \\
0 & \frac{\sqrt{3}}{2} & -\frac{\sqrt{3}}{2}
\end{array}\right] \cdot\left[\begin{array}{l}
\rho_{A}(k) \\
\rho_{B}(k) \\
\rho_{C}(k)
\end{array}\right] } \\
= & \frac{1}{E} \cdot \sqrt{\frac{3}{2}} \cdot \boldsymbol{M}^{-1}(k) \cdot \boldsymbol{G}^{-1} \cdot\left(\underline{X}^{\#}-\boldsymbol{F}(k) \cdot \underline{X}(k)-\underline{H}(k)\right) \\
& \equiv\left[\begin{array}{l}
\rho_{1}(k) \\
\rho_{2}(k)
\end{array}\right]
\end{aligned}
$$

The resolution of (15) gives one degree of freedom that can be added to adapt duty cycles with the desired modulation pattern. Many kinds of modulation patterns are reported [13]. Indeed different duty cycle vectors can lead to same mean value of stator voltages during a modulation period.

For a conventional sequence as presented in Fig. 5, configurations $0\left(u_{A}=u_{B}=u_{C}=0\right)$ and $7\left(u_{A}=u_{B}=u_{C}=1\right)$ corresponding to null voltages are applied for same duration. This is obtained by choosing $\rho_{C}=\frac{\rho_{7}}{2}$ and $\rho_{B}=1-\frac{\rho_{7}}{2}$, where $\rho_{7}$ is the duty cycle for the null voltage application. In this case, it can be seen that $\rho_{B}+\rho_{C}=1$ and $\rho_{B}>\rho_{A}>\rho_{C}$. Any possible cases are be summarized by (16) and (17):

$$
\begin{aligned}
& \rho_{B}+\rho_{C}=1 \Leftrightarrow\left\{\begin{array}{l}
\rho_{B}>\rho_{A}>\rho_{C} \\
\rho_{C}>\rho_{A}>\rho_{B}
\end{array}\right. \\
& \rho_{A}+\rho_{C}=1 \Leftrightarrow\left\{\text { or } \begin{array}{l}
\rho_{A}>\rho_{B}>\rho_{C} \\
\rho_{C}>\rho_{B}>\rho_{A}
\end{array}\right. \\
& \rho_{A}+\rho_{B}=1 \Leftrightarrow\left\{\text { or } \begin{array}{l}
\rho_{B}>\rho_{C}>\rho_{A} \\
\rho_{A}>\rho_{C}>\rho_{B}
\end{array}\right. \\
& \min \left(\rho_{A}, \rho_{B}, \rho_{C}\right)=\frac{\rho_{7}}{2} \\
& \max \left(\rho_{A}, \rho_{B}, \rho_{C}\right)=1-\frac{\rho_{7}}{2}
\end{aligned}
$$

So (18) and (19) characterizes the chosen modulation pattern.

$$
\max \left(\rho_{A}, \rho_{B}, \rho_{C}\right)+\min \left(\rho_{A}, \rho_{B}, \rho_{C}\right)=1
$$




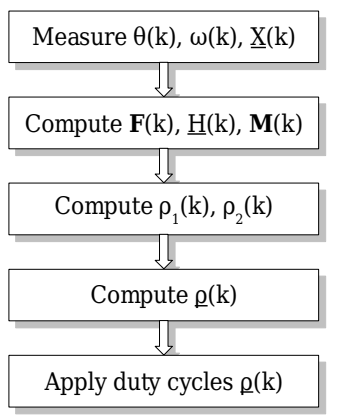

Fig. 6. Steps of PWM Predictive Control

$$
\max \left(\rho_{A}, \rho_{B}, \rho_{C}\right)-\min \left(\rho_{A}, \rho_{B}, \rho_{C}\right)=1-\rho_{7}
$$

One of them, for example (18), can be added to (15) for determining duty cycles $\rho(k)$.

For the example of Fig. $5\left(\rho_{B}+\rho_{C}=1\right)$, (15) becomes (20).

$$
\left[\begin{array}{ccc}
1 & -\frac{1}{2} & -\frac{1}{2} \\
0 & \frac{\sqrt{3}}{2} & -\frac{\sqrt{3}}{2} \\
0 & 1 & 1
\end{array}\right] \cdot\left[\begin{array}{c}
\rho_{A}(k) \\
\rho_{B}(k) \\
\rho_{C}(k)
\end{array}\right]=\left[\begin{array}{c}
\rho_{1}(k) \\
\rho_{2}(k) \\
1
\end{array}\right]
$$

For the three possibilities offered by (18) $\left(\rho_{A}+\rho_{B}=1\right.$, $\rho_{B}+\rho_{C}=1$ or $\rho_{A}+\rho_{C}=1$ ), the obtained matrix is a constant invertible matrix, and its inverse can be calculated off-line.

$$
\begin{aligned}
& {\left[\begin{array}{ccc}
1 & -\frac{1}{2} & -\frac{1}{2} \\
0 & \frac{\sqrt{3}}{2} & -\frac{\sqrt{3}}{2} \\
0 & 1 & 1
\end{array}\right]^{-1}=\left[\begin{array}{ccc}
1 & 0 & \frac{1}{2} \\
0 & \frac{\sqrt{3}}{3} & \frac{1}{2} \\
0 & -\frac{\sqrt{3}}{3} & \frac{1}{2}
\end{array}\right]} \\
& {\left[\begin{array}{ccc}
1 & -\frac{1}{2} & -\frac{1}{2} \\
0 & \frac{\sqrt{3}}{2} & -\frac{\sqrt{3}}{2} \\
1 & 0 & 1
\end{array}\right]^{-1}=\left[\begin{array}{ccc}
\frac{1}{2} & \frac{\sqrt{3}}{6} & \frac{1}{2} \\
-\frac{1}{2} & \frac{\sqrt{3}}{2} & \frac{1}{2} \\
-\frac{1}{2} & -\frac{\sqrt{3}}{6} & \frac{1}{2}
\end{array}\right]} \\
& {\left[\begin{array}{cccc}
1 & -\frac{1}{2} & -\frac{1}{2} \\
0 & \frac{\sqrt{3}}{2} & -\frac{\sqrt{3}}{2} \\
1 & 1 & 0
\end{array}\right]^{-1}=\left[\begin{array}{ccc}
\frac{1}{2} & -\frac{\sqrt{3}}{\sqrt{3}} & \frac{1}{2} \\
-\frac{1}{2} & \frac{\sqrt{3}}{6} & \frac{1}{2} \\
-\frac{1}{2} & -\frac{\sqrt{3}}{2} & \frac{1}{2}
\end{array}\right]}
\end{aligned}
$$

It is then possible to determine algebraically duty cycles $\rho(k)$. Indeed a possible computing method consist in computing duty cycle vectors with (21), (22) and (23). Among the three obtained vectors one and only one is consistent with the hypothesis $(16)^{1}[14]$. This duty cycle vector can then be selected for application during the next modulation period.

This method of duty cycles calculation is independent to the section where the voltage space vector is and any trigonometrical function is necessary. The overall control scheme is summarised in Fig. 6.

\section{EXPERIMENTAL STUDY}

\section{A. Hardware and Software}

The experiment study was conducted with an equipment composed of a 1.6KW PMSM (parameters given in Tab. II) with a 4096-pulse incremental encoder. Another identical PMSM is used as a load torque generator.

A commercial $15 \mathrm{~kW}$ three-phase inverter based on Insulated-Gate Bipolar Transistors (IGBTs) is supplied by two

\footnotetext{
${ }^{1}$ For example, a duty cycle vector computed with (21) assume $\rho_{B}+\rho_{C}=$ 1. Then it must verify $\rho_{B}>\rho_{A}>\rho_{C}$ or $\rho_{C}>\rho_{A}>\rho_{B}$.
}

TABLE II

PARAMETERS OF THE PMSM

\begin{tabular}{crl}
\hline \hline Rated Torque & 5 & $\mathrm{Nm}$ \\
Rated Speed & 3000 & $\mathrm{rpm}$ \\
$R$ & 2.06 & $\Omega$ \\
$L$ & 9.15 & $\mathrm{mH}$ \\
$\phi$ & 290 & $\mathrm{mWb}$ \\
Number of pole pairs (p) & 3 & \\
\hline \hline
\end{tabular}

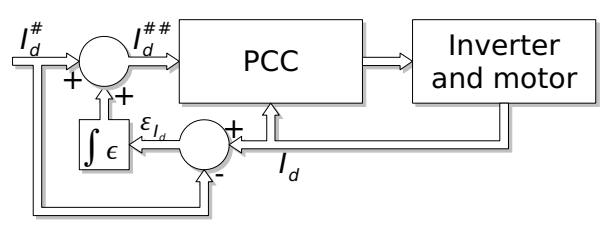

Fig. 7. Added Integral Compensation

voltage sources XANTREX which provide $540 \mathrm{~V}$ with current limitation of about 10A. The dead-time is fixed to $3 \mu \mathrm{s}$. Three LEM current sensors (LEM LA 100P) are used.

The direct predictive control (DPC) and the proposed PWM predictive control (PPC) algorithms are implemented in C language and computations are performed by a DSpace DS1104 controller board. Data recording and reference value tuning are performed within the ControlDesk environment except for spectra $^{2}$.

The compensation method proposed by [12] is used for both control schemes in order to take into account the calculation time delay, i.e. the duration between the current measure and the application of the control vector.

As proposed in [10] and [15], an integral compensation is added to compensate steady state errors for both control schemes. Reference values are compared to actual values (e.g. for $\left.I_{d}, \varepsilon_{I_{d}}(k)=I_{d}^{\#}(k)-I_{d}(k)\right)$ and error's integrals are computed (e.g. for $\left.I_{d}, \int \varepsilon_{I_{d}}(k)=\frac{\varepsilon_{I_{d}}(k-1)+\varepsilon_{I_{d}}(k)}{2} T\right)$. For predictive control schemes, corrected reference values are given by $I_{d}^{\# \#}(k)=I_{d}^{\#}(k)+\frac{1}{T_{i}} \int \varepsilon_{I_{d}}(k)$, where $T_{i}$ is set to 10 times the sampling period. During transient operation, to overcome overshoots due to windup of the integral compensator, this corrector is not active and $\int \varepsilon_{I_{d}}$ and $\int \varepsilon_{I_{q}}$ are set to 0 . This additional loop is illustrated on Fig. 7.

\section{B. Experimental Conditions}

For a PMSM, the electromagnetic torque is proportional to the current $I_{q}$. Then the minimization of the Joule power losses leads to fix the current $I_{d}$ to zero. Consequently, reference values are $I_{d}^{\#}=0$ and $I_{q}^{\#}$ proportional to the desired torque $T e^{\#}\left(I_{q}^{\#}=\frac{T e^{\#}}{p * \phi}\right)$.

The comparative study between DPC and PPC is performed for different operating points. Firstly, the desired torque is set very smaller than the nominal value $\left(I_{q}^{\#}=1 \mathrm{~A}\right)$. It is not possible to obtain high speed with this small torque. The maximum speed that can be obtained is $\approx 200 \mathrm{rpm}$. Secondly, for nominal torque $\left(I_{q}^{\#}=5.75 \mathrm{~A}\right)$, two load conditions corresponding to high rotor speed $(\approx 2100 \mathrm{rpm})$ and low rotor speed $(\approx 200 \mathrm{rpm})$ are tested.

${ }^{2}$ Spectra are recorded with Tektronic hardware: a A 6302 current sensor, a AM 503 current probe amplifier and a TDS 7045.Measures are sampled at $1 \mu$ s during $2 \mathrm{~s}$. The $125 \mathrm{kHz}$ bandwidth spectrum is obtained using a $1 \mathrm{~s}$ wide Gaussian window. 


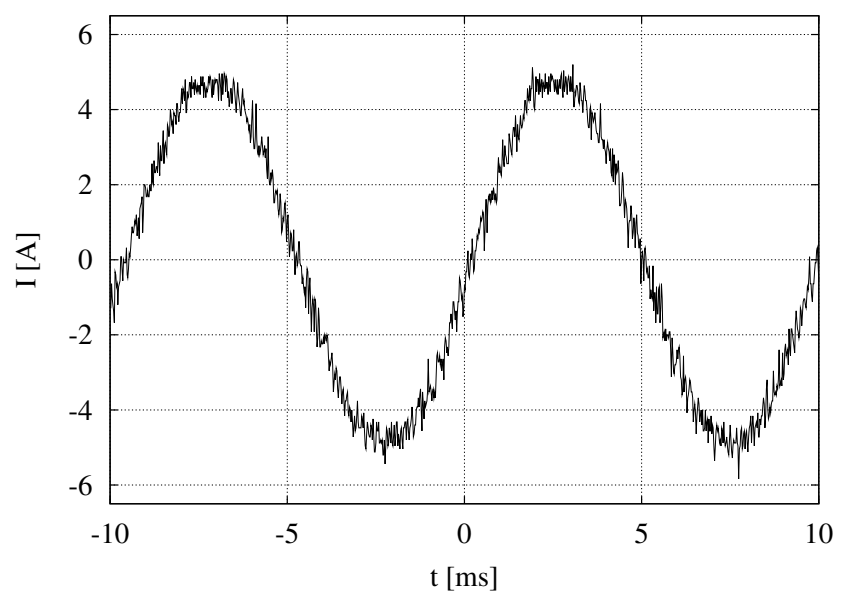

(a) DPC

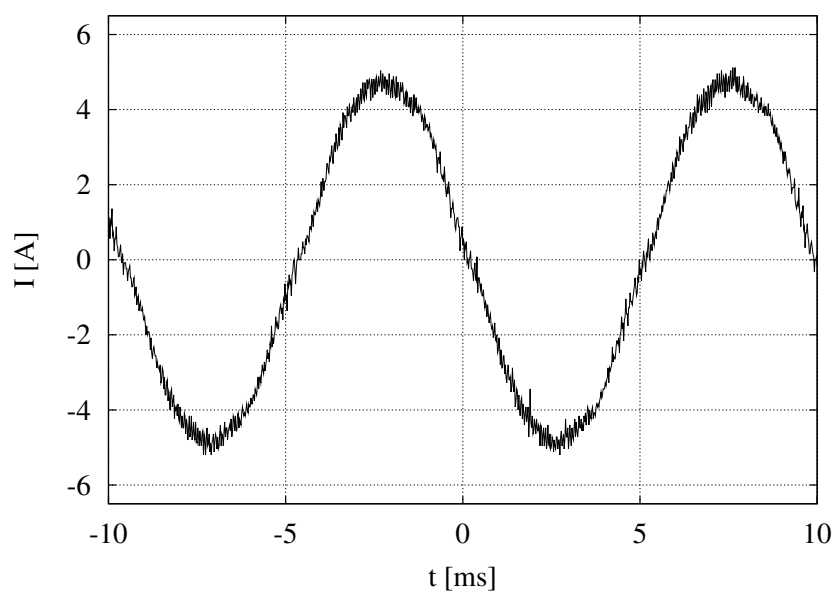

(b) PPC

Fig. 8. Phase current during steady state operation at $2000 \mathrm{rpm}$ with $I_{d}^{\#}=0 \mathrm{~A}$ and $I_{q}^{\#}=5.75 \mathrm{~A}$

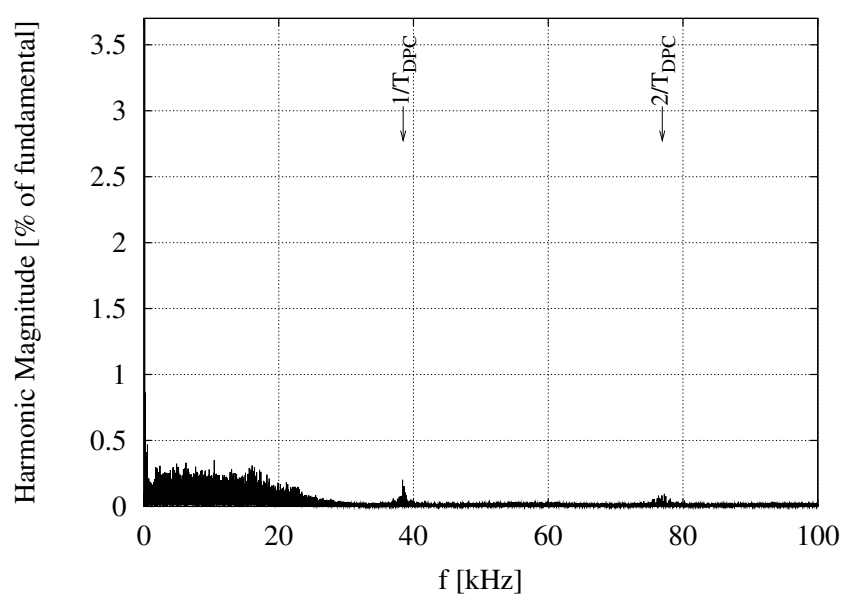

(a) DPC

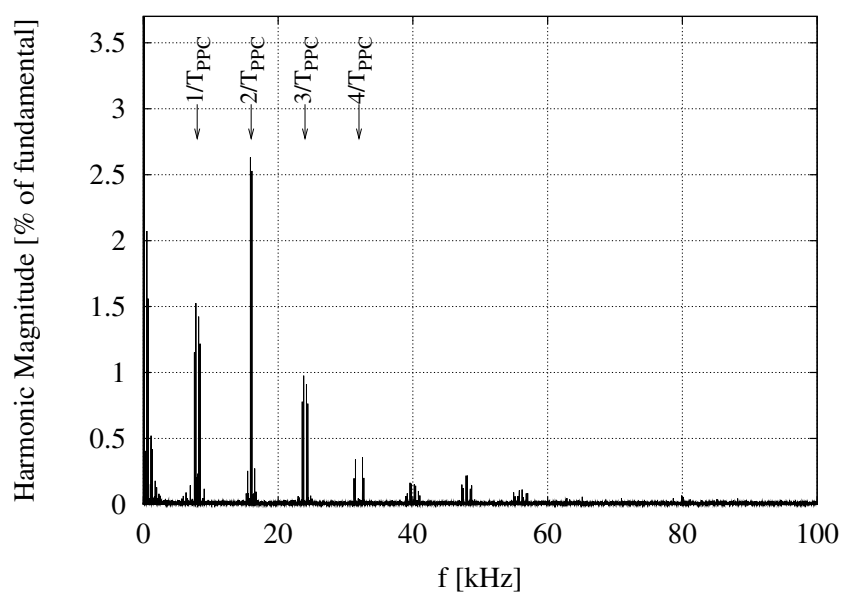

(b) PPC

Fig. 9. Phase current spectrum at 2000rpm with $I_{d}^{\#}=0 \mathrm{~A}$ and $I_{q}^{\#}=5.75 \mathrm{~A}$

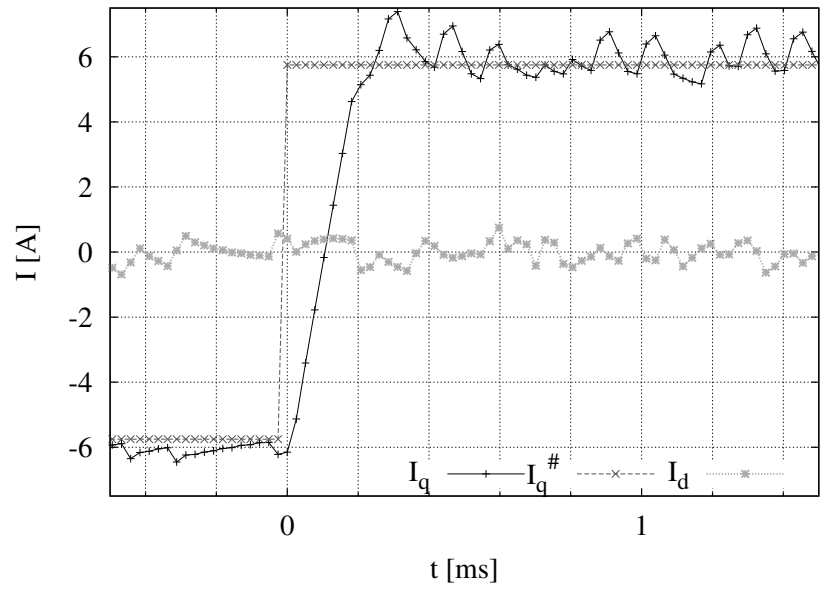

(a) DPC

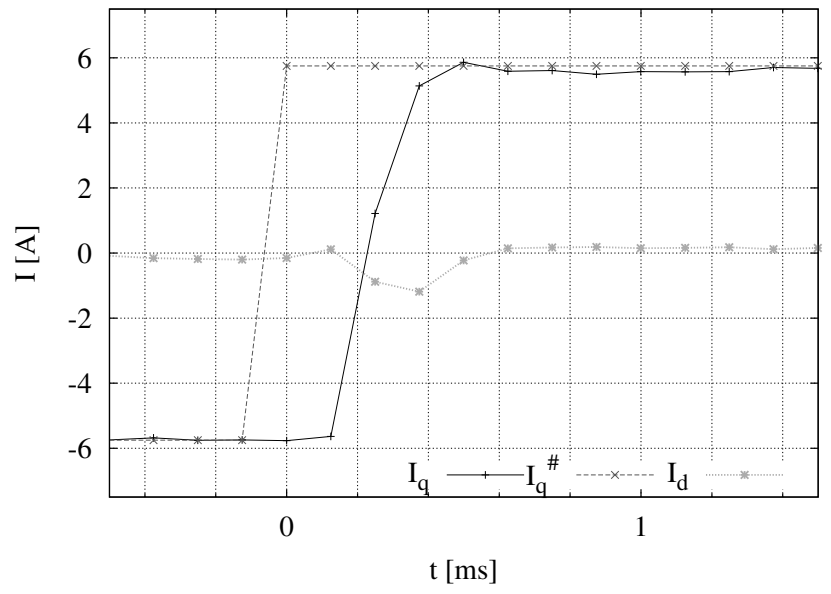

(b) PPC

Fig. 10. Phase currents in the rotor frame during transient operation at $2000 \mathrm{rpm}$ with $I_{d}^{\#}=0 \mathrm{~A}$ and $I_{q}^{\#}= \pm 5.75 \mathrm{~A}$ 
The dynamic performances of both control schemes are compared for each of these operating points. Transient operations are obtained by changing the sign of the torque desired value.

It is worth to note that the tested control schemes are equivalent to a torque controls. Indeed there is no speed loop. Generally torque controllers are used inside a speed loop. It is not the case in the presented experiments. Angular speed is not controlled, it is just an outcome of test bench mechanical parameters like inertia, frictions or load torque.

\section{Sampling periods}

DPC computations are started with a timer interrupt. As there are only 7 possible directions for the state vector during each computing period, the reference point could not be exactly reached and the smallest the sampling period $\mathrm{T}$, the lowest the oscillation amplitude. This leads to choose a sampling period as short as possible in order to maintain the state vector as near as possible to the reference point. Then the sampling period is fixed just larger than the computation duration i.e. $26 \mu$ s here.

With DPC, between two computation cycles, the number of leg state changes can be 0 (if $i_{\text {select }}(k)=i_{\text {select }}(k+1)$ ), 1 (e.g. $i_{\text {select }}(k)=7$ and $\left.i_{\text {select }}(k+1)=2\right), 2$ (e.g. $i_{\text {select }}(k)=2$ and $i_{\text {select }}(k+1)=4$ ) or even 3 (e.g. $i_{\text {select }}(k)=1$ and $\left.i_{\text {select }}(k+1)=4\right)$. So, DPC leads to an unpredictable variable switching frequency. Experimental results show that the mean switching frequency depends from the operating point (e.g. the mean number of leg state changes between two computing periods is 0.84 at $200 \mathrm{rpm} / 0.9 \mathrm{Nm}, 1.06$ at $200 \mathrm{rpm} / 5 \mathrm{Nm}$ or 1.25 at $2000 \mathrm{rpm} / 5 \mathrm{Nm}$ ).

For PPC, at each sampling period, there are six switching (Fig. 5). In order to have a similar switching frequency at high speed / high torque, the modulation period of the PPC scheme is fixed to $125 \mu \mathrm{s}\left(6^{*} 26 / 1.25\right)$ although the period could be very low since the computing duration is almost the same for both control schemes.

\section{Results}

In this paper, due to the lack of space, results are only shown for one operating point (high torque and low speed). Figures for other conditions are available on line [16].

Phase currents can be compared with Fig. 8. With DPC, oscillations are quite independent of the operating point. With PPC, oscillations are a little larger for high torque and the larger the speed, the larger the amplitude of oscillations; the presented case is then the less favorable for PPC. However oscillations are smaller for PPC than for DPC for every case.

Phase current spectra are shown in Fig. 9 for the operation point considered. The harmonic distribution of PPC (Fig. 9(b)) is very well concentrated near the sampling frequency $(8 \mathrm{kHz})$ and its multiples while the harmonic components of DPC (Fig. 9(a)) are distributed over a large low-frequency span. For the other tested operating point, it can be seen that under PPC, the harmonic content in phase current is significantly reduced.

For both control schemes, the transient operation (Fig. 10) is very fast (almost $200 \mu \mathrm{s}$ ). There is no overshoot for PPC (Fig. 10(b)) and it is quite small for DPC (Fig. 10(a). It can be seen that the transient operation of the current on the q-axis has no important consequence for the current control on the d-axis.

\section{CONCLUSION}

Two predictive current controls for PMSM has been presented and experimentally compared. The dynamic performance of DPC and PPC are similar but some superiorities can be noted with PPC since its current ripples are generally reduced and its current harmonic distribution is well concentrated near known frequencies in the high-frequency area. Computation durations for both controls are similar. However, if the same switching frequency is required, PPC leads to a very larger sampling periods by determining more than one configuration of the converter during a computation period. Then the real-time constraint is less than for DPC, so cheaper controllers can be used. Furthermore, at the opposite to DPC, PPC allows to have a known and constant switching frequency. It can be noted also that the proposed method of duty cycle calculation for PPC is easy to implement without sines and cosines computations.

\section{REFERENCES}

[1] J. Rodriguez, J. Pontt, C. A. Silva, P. Correa, P. Lezana, P. Cortes, and U. Ammann, "Predictive current control of a voltage source inverter," IEEE Trans. Ind. Electron., vol. 54, pp. 495-503, Feb. 2007.

[2] J. Rodriguez, J. Pontt, C. Silva, P. Cortes, U. Amman, and S. Rees, "Predictive current control of a voltage source inverter," 2004. PESC 04. 2004 IEEE 35th Annual Power Electronics Specialists Conference, vol. 3, pp. 2192-2196, June 20-25, 2004.

[3] X. Lin-Shi, F. Morel, A. M. Llor, B. Allard, and J. M. Retif, "Implementation of Hybrid Control for Motor Drives," IEEE Trans. Ind. Electron., vol. 54, no. 4, pp. 1946-1952, Aug. 2007.

[4] P. Cortes, J. Rodriguez, R. Vargas, and U. Ammann, "Cost Functionbased Predictive Control for Power Converters," in IEEE Industrial Electronics, IECON 2006 - 32nd Annual Conference on, Paris, France, Nov. 2006, pp. 2268-2273.

[5] V. Ambrozic, R. Fiser, and D. Nedeljkovic, "Direct current control-a new current regulation principle," IEEE Trans. Power Electron., vol. 18, pp. 495-503, Jan. 2003.

[6] G. S. Buja and M. P. Kazmierkowski, "Direct torque control of PWM inverter-fed AC motors - a survey," IEEE Trans. Ind. Electron., vol. 51, no. 4, pp. 744-757, Aug. 2004.

[7] H. Abu-Rub, J. Guzinski, Z. Krzeminski, and H. A. Toliyat, "Predictive current control of voltage-source inverters," IEEE Trans. Ind. Electron., vol. 51, no. 3, pp. 585-593, June 2004.

[8] P. Correa, M. Pacas, and J. Rodriguez, "Predictive torque control for inverter-fed induction machines," IEEE Trans. Ind. Electron., vol. 54, no. 2, pp. 1073-1079, Apr. 2007.

[9] L. Springob and J. Holtz, "High-bandwidth current control for torqueripple compensation in PM synchronous machines," IEEE Trans. Ind. Electron., vol. 45, no. 5, pp. 713-721, Oct. 1998.

[10] H. Le-Huy, K. Slimani, and P. Viarouge, "Analysis and implementation of a real-time predictive current controller for permanent-magnet synchronous servo drives," IEEE Trans. Ind. Electron., vol. 41, no. 1, pp. 110-117, Feb. 1994.

[11] O. Kukrer, "Discrete-time current control of voltage-fed three-phase PWM inverters," IEEE Trans. Power Electron., vol. 11, no. 2, pp. 260269, Mar. 1996.

[12] H.-T. Moon, H.-S. Kim, and M.-J. Youn, "A discrete-time predictive current control for PMSM," IEEE Trans. Power Electron., vol. 18, pp. 464-472, Jan. 2003.

[13] H. W. van der Broeck, H. C. Skudelny, and G. V. Stanke, "Analysis and realization of a pulsewidth modulator based on voltage space vectors," IEEE Trans. Ind. Applicat., vol. 24, pp. 142-150, Jan./Feb. 1988.

[14] F. Morel, "Commandes directes appliquées à une machine synchrone à aimants permanents alimentée par un onduleur triphasé à deux niveaux ou par un convertisseur matriciel triphasé," Ph.D. dissertation, INSA de Lyon, 2007.

[15] P. Wipasuramonton, Z. Q. Zhu, and D. Howe, "Predictive current control with current-error correction for PM brushless AC drives," IEEE Trans. Ind. Applicat., vol. 42, no. 4, pp. 1071-1079, July/Aug. 2006.

[16] F. Morel, X. Lin Shi, J.-M. Rétif, and B. Allard, "Exaustive experimental results available on-line," http://klimt2.insa-lyon.fr/florent/PESC08/ annexes.pdf. 